Marcus A. Mininger

\title{
Uncovering the Theme of Revelation in Romans 1:16-3:26
}

Discovering a New Approach to Paul's Argument

[Das verborgene Thema der Offenbarung in Römer 1,16-3,26. Ein neuer Zugang zur Argumentation des Paulus.]

Veröffentlicht auf Englisch.

Bisherige Untersuchungen von Röm 1,16-3,26 konzentrieren sich auf das Heil des Einzelnen oder gesellschaftliche

MARCUS A. MININGER

Uncovering the

Theme of Revelation in

Romans 1:16-3:26

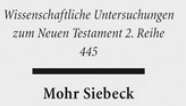

2017. XVI, 410 Seiten. WUNT II 445

ISBN 978-3-16-155673-9

DOI 10.1628/978-3-16-155673-9

eBook PDF 109,00€

ISBN 978-3-16-155649-4

fadengeheftete Broschur 109,00€
Beziehungen und verursachten eine Fülle interpretativer Zwickmühlen. Marcus A. Mininger entwickelt einen neuen Ansatz, der diese Perspektiven miteinbezieht, aber darüber hinausgeht, indem er mit einem neuen Ansatz darlegt, dass das Thema der Offenbarung sich beinahe unbemerkt durch die Argumentation des Paulus zieht. Mehr als einen Beweis für Sünde oder soziale Gleichstellung, liefert Paulus eine Bestandsaufnahme zahlreicher sichtbarer Offenbarungen, in denen ansonsten unsichtbare Gegebenheiten wie der Zorn Gottes, die Macht der Sünde und die Gerechtigkeit Gottes in ihrem Einfluss, den sie auf verschiedene Menschen ausüben, behandelt wurden. Aus dieser Sicht werden die Gründe für Paulus' Argumentation deutlich, einschließlich der »Problemtexte« wie Röm 2 und 3,1-8, da Paulus beweist, dass das Evangelium, nicht das Gesetz die Macht der Sünde überwindet und dass die Gerechtigkeit Gottes in diesem Zeitalter immer im Kontrast zur Sterblichkeit des Menschen steht.

Marcus A. Mininger Born 1976; 2002 MDiv; 2009 ThM; 2017 PhD; 2012-16 Assistant Professor of New Testament, MidAmerica Reformed Seminary; since 2016 Associate Professor of New Testament, Mid-America Reformed Seminary.
Jetzt bestellen:

https://mohrsiebeck.com/buch/uncovering-the-theme-of-revelation-in-romans-116-326-9783161556739?no_cache=1 order@mohrsiebeck.com

Telefon: +49 (0)7071-923-17

Telefax: +49 (0)7071-51104 